\title{
Implementing open educational resources in digital education
}

\author{
Hengtao Tang ${ }^{1}$ () \\ Accepted: 6 November 2020 / Published online: 19 November 2020 \\ (c) Association for Educational Communications and Technology 2020
}

\begin{abstract}
The outbreak of COVID-19 leads to an increasing demand for online educational resources to continue teaching and learning. Open educational resources (OER), with the benefits of cost-saving and open licenses, have great potential in facilitating the rapid transition to digital education, but concerns about whether OER decrease the effectiveness of student learning remains unsolved. Hilton's review article (2016) provides synthesized evidence stating that OER can help decrease college students' textbook spending without undermining student learning effectiveness. It is also noteworthy that implementing OER in digital education needs additional considerations beyond the efficacy of OER. Therefore, this special issue article extends Hilton's (2016) synthesized findings by presenting four additional perspectives in research, design, culture, practice about implementing OER in digital education.
\end{abstract}

Keywords Open educational resources · Digital education · Efficacy · Openness · COVID19

Open educational resources (OER) are free, open-licensed educational resources that users can retain, reuse, revise, remix, and redistribute for personalized needs (Wiley \& Hilton, 2018). Hilton (2016), synthesizing evidence about the efficacy of OER from 16 studies, argued that learning with OER saved college students' educational cost without undermining their learning achievement. Some of the reviewed studies (e.g., Feldstein et al. 2012; Hilton and Laman 2012) even supported that OER improved college students' grade or retention. Most college instructors and students in the reviewed articles were also positive about the quality of OER (Hilton 2016). Therefore, Hilton (2016) claimed OER as an efficient low-cost alternative to commercial textbooks in higher education. Hilton (2016) also explained that the review was limited by a small number of relevant studies available at the time of writing, especially few studies with sound research design. Future research about OER efficacy needs to develop a well-refined research design to further confirm the causality between OER and learning effectiveness.

Hengtao Tang

htang@mailbox.sc.edu

1 Department of Educational Studies, University of South Carolina, Columbia, SC 29208, USA 


\section{Implications for shifting to digital education}

This review is significant for educators to provide personalized instruction during the shift to digital learning in higher education, especially when the shift (1) needs to be accomplished in a short timeframe with a shortage of resources and (2) the transition is challenged by a lack of sufficient funding support. The outbreak of COVID-19 resulted in new waves of online courses offerings in higher education, but when responding to abrupt changes in course delivery, college instructors especially novice online instructors may have hardships in addressing each student' needs in online settings due to time constraints and limited access to resources and support (Lin and Tang 2017). In Hilton's (2016) review, OER provide college instructors with enriched options of resources to rapidly respond to the emergent situation, including a variety of easily accessible materials (e.g., open textbooks, online repositories) across multiple domains (e.g., science, psychology, mathematics) that college instructors can personalize (e.g., retain, reuse, revise, remix, and redistribute) to help each student learn effectively. On the other hand, OER potentially invigorate social justice in digital education during the societal turmoil. Hilton (2016) indicates OER can provide each student with free content of similar efficacy to that in commercial textbooks, including low socioeconomic status (SES) students (Hilton et al. 2013; Read et al. 2020). In the midst of societal turmoil and uncertainty, saving low SES students' educational costs is the prerequisite to maintain the effectiveness of online learning.

\section{Perspectives beyond efficacy}

Hilton's (2016) review systematically evaluates the efficacy of OER in higher education. In addition to existing studies showing the effectiveness of OER, more need to be done regarding four additional perspectives.

First, Hilton's (2016) review outlines future directions for research and scholarship about OER. One research direction built upon this review is to look beyond the efficacy of OER. OER scholars realized that only focusing on the cost-saving benefits undermines the potential of OER in digital education. Open scholars (e.g., Kimmons 2016; Wiley and Hilton 2018) bring the spotlight to the merits of openness and thus call for effort from scholars and educators to look into open educational practices (OEP). OEP broadly denote practices of adapting, implementing, and sharing OER in contextualized ways (Tang et al. 2020). For example, Wiley et al. (2017) implemented OEP in high school digital photography course by allowing students to create and then share their artifacts with open licenses beyond classrooms rather than merely disposing homework after being graded. In short, open scholars are recommended to investigate and support how OEP turns the homework into renewable assignments and extends the merit of openness to benefit a broader community (Wiley et al. 2017).

Second, Hilton's (2016) review claims OER as cost-effective and open-licensed alternatives to traditional textbooks in higher education, which can also uphold the need for cost reduction and differentiated instruction in K-12 settings. Textbooks are the sole channel for K-12 teachers to deliver pre-packed knowledge to students, but are not sufficient to ensure each student learns effectively (Tang et al. 2020). Teachers can adopt OER for differentiated instruction, but they need to overcome various barriers such as shortage of OER aligned with course standards, especially for subjects such as special education and 
laboratory studies (Kimmons 2016; Tang 2020). Education policymakers and school leaderships need to implement effective interventions, such as a quality assurance system (Tang 2020 ) or a teacher institute specialized on OER (Kimmons 2016), to improve K-12 teachers' intention of using, adapting, and sharing OER and thus support differentiated instruction in this setting.

Third, Hilton's (2016) review attribute teachers' positive perception to OER's affordance of personalizing instructional materials. OER allow personalized instruction, so the capacity of granularly assessing student individualized needs is critical (Genesereth et al. 2020). A collaborative project among Stanford University, Rice University, and OpenStax developed intelligent textbooks using artificial intelligence (AI) and knowledge graphs to predict learner needs and provide proximal resources (Genesereth et al. 2020). Beyond efficacy considerations, scholars and industrial practitioners can consider integrating AI to present granular insights of design and development for future implementation and thereby improve the relevance of open contents to learner demands (Koć-Januchta et al. 2020).

Fourth, Hilton's (2016) review (e.g., Hilton et al. 2013) shows OER allow students who otherwise cannot afford textbooks with open and free access to educational resources. This cost-saving benefit creates the possibility for invigorating social justice. However, it remains uncertain whether the population in great needs for OER are the primary beneficiaries. For example, teachers in underdeveloped areas may not efficiently use or adapt OER due to the second-level digital divide in education (Tang and Bao 2020). This limits the capacity of OER in serving the targeted beneficiaries. On the other hand, underserved groups barely get their own voices heard in open education (Tang and Bao 2020). Educators from underserved groups should not simply translate the content in their local language and reuse it without considering whether to represent their voice and to fit local contexts (Hodgkinson-Williams and Trotter 2018). Encouraging those underserved groups to raise their voice in OER is necessary to fulfill OER's potential of invigorating social justice.

Acknowledgements The author would like to thank Drs. John Hilton III and Royce Kimmons for their support with this article.

\section{Compliance with ethical standards}

Conflict of interest The authors declare that they have no conflict of interests.

Informed consent The authors declare that no informed consent is needed since no participants are included.

Research involving human and animal rights The authors declare that the article does not involve human participants and/or animals.

\section{References}

Feldstein, A., Martin, M., Hudson, A., Warren, K., Hilton, J., \& Wiley, D. (2012). Open textbooks and increased student access and outcomes. European Journal of Open Distance and E-Learning. Retrieved from http://www.eurodl.org/index.php?article=533.

Genesereth, M., Baraniuk, R., Musen, M., Heller, C., \& Chaudhri, V. (2020). Textbook open knowledge network. Retrieved from https://web.stanford.edu/ vinayc/tokn/docs/1.\%20Public_Executive_Summa ry_v11.pdf.

Hilton, J. (2016). Open educational resources and college textbook choices: A review of research on efficacy and perceptions. Educational Technology Research and Development, 64(4), 573-590. 
Hilton, J., \& Laman, C. (2012). One college's use of an open psychology textbook. Open Learning: The Journal of Open and Distance Learning, 27(3), 201-217.

Hilton, J., Gaudet, D., Clark, P., Robinson, J., \& Wiley, D. (2013). The adoption of open educational resources by one community college math department. The International Review of Research in Open and Distance Learning, 14(4), 37-50.

Hodgkinson-Williams, C. A., \& Trotter, H. (2018). A social justice framework for understanding open educational resources and practices in the global south. Journal of Learning for Development-JL4D, 5(3).

Kimmons, R. (2016). Expansive openness in teacher practice. Teachers College Record, 118(9), 1-34 https ://www.tcrecord.org/Content.asp?ContentId=21521.

Koć-Januchta, M. M., Schönborn, K. J., Tibell, L. A., Chaudhri, V. K., \& Heller, H. C. (2020). Engaging with biology by asking questions: Investigating students' interaction and learning with an artificial intelligence-enriched textbook. Journal of Educational Computing Research. https://doi. org/10.1177/0735633120921581.

Lin, Y. J., \& Tang, H. (2017). Exploring student perceptions of the use of open educational resources to reduce statistics anxiety. Journal of Formative Design in Learning, 1(2), 110-125.

Read, K., Tang, H., Dhamija, A., \& Bodily, B. (2020). Understanding the impact of OER courses in relation to student socioeconomic status and employment. International Journal of Open Educational Resources, 3(1) Retrieved from https://ijoer.org/understanding-the-impact-of-oer-courses-in-relationto-student-socioeconomic-status-and-employment. https://doi.org/10.18278/ijoer.3.1.5.

Tang, H. (2020). A qualitative inquiry of k-12 teachers' experience with open educational practices: Perceived benefits and barriers of implementing open educational resources. The International Review of Research in Open and Distance Learning, 21(3), 211-229.

Tang, H., \& Bao, Y. (2020). Social justice and K-12 teachers' effective use of OER: A cross-cultural comparison by nations. Journal of Interactive Media in Education, 2020(1). https://doi.org/10.5334/ jime.576.

Tang, H., Lin, Y. J., \& Qian, Y. (2020). Understanding K-12 teachers' intention to adopt open educational resources: A mixed methods inquiry. British Journal of Educational Technology, 51(6), 2558-2572. https://doi.org/10.1111/bjet.12937.

Wiley, D., \& Hilton, J. L., III. (2018). Defining OER-enabled pedagogy. The International Review of Research in Open and Distance Learning, 19(4), 133-147.

Wiley, D., Webb, A., Weston, S., \& Tonks, D. (2017). A preliminary exploration of the relationships between student-created OER, sustainability, and students' success. International Review of Research in Open \& Distance Learning, 18(4), 60-69.

Publisher's Note Springer Nature remains neutral with regard to jurisdictional claims in published maps and institutional affiliations.

Dr. Hengtao Tang is an Assistant Professor in the Department of Educational Studies at the University of South Carolina. His research interests include learning analytics, self-regulated learning, STEM education, and open education. Dr. Tang is also an Open Educational Resources research fellow of the Open Education Group sponsored by the William and Flora Hewlett Foundation. 